\title{
Association of three missense mutations in the homocysteine-related MTHFR and MTRR gene with risk of polycystic ovary syndrome in Southern Chinese women
}

Wanqin Feng ${ }^{1+}$, Yan Zhang ${ }^{2 \dagger}$, Yuan Pan ${ }^{3}$, Yi Zhang ${ }^{3}$, Minjuan Liu ${ }^{1,4}$, Yuxin Huang ${ }^{5}$, Yuanling Xiao ${ }^{5}$, Wenyu Mo ${ }^{1}$, Junjie Jiao ${ }^{6}$, Xiaoyang Wang ${ }^{1}$, Dan Tian $^{5}$, Lixia Yang ${ }^{7}$ and Ying Ma ${ }^{1 *}$ (D

\begin{abstract}
Background: The etiology between homocysteine and polycystic ovary syndrome (PCOS) is unclear. In humans, the level of homocysteine is mainly affected by two enzymes: methylene tetrahydrofolate reductase (MTHFR) and methionine synthase reductase (MTRR). While the activity of these two enzymes is mainly affected by three missense mutations, namely C677T (MTHFR), A1298C (MTHFR), and A66G (MTRR). This study aims to examine the association between the three missense mutations and PCOS and investigate whether the three missense mutations exerted their effect on PCOS by affecting the homocysteine level.
\end{abstract}

Methods: A case-control study was designed, comprising 150 people with PCOS and 300 controls. Logistic regression analysis was used to assess the association between the three missense mutations and PCOS. Linear regression analysis was used to assess the association between the three missense mutations and the homocysteine level. Mediation analysis was used to investigate whether the three missense mutations exerted their effect on PCOS by affecting the homocysteine level.

Results: Following adjustments and multiple rounds of testing, MTHFR A1298C was found to be significantly associated with PCOS in a dose-dependent manner (compared to $A A, O R=2.142$ for $A C \& O R=3.755$ for $C C ; P<$ 0.001). MTRR A66G was nominally associated with PCOS. Mutations in MTHFR A1298C and MTRR A66G were significantly associated with the homocysteine level. Mediation analysis suggested the effect of MTHFR A1298C on PCOS was mediated by homocysteine.

Conclusions: MTHFR A1298C and MTRR A66G were associated with PCOS, and MTHFR A1298C might affect the risk of PCOS by influencing the homocysteine level.

Keywords: Polycystic ovary syndrome, MTHFR, MTRR, Folic acid, Homocysteine

\footnotetext{
* Correspondence: mayingwuzhuoyi@126.com

'Wanqin Feng and Yan Zhang contributed equally to this work.

'Department of Gynecology, Obstetrics and Gynecology Center, Zhujiang

Hospital, Southern Medical University, No.253, Gongye Middle Avenue,

Haizhu District, 510280 Guangzhou, Guangdong, China

Full list of author information is available at the end of the article
}

(c) The Author(s). 2021 Open Access This article is licensed under a Creative Commons Attribution 4.0 International License, which permits use, sharing, adaptation, distribution and reproduction in any medium or format, as long as you give appropriate credit to the original author(s) and the source, provide a link to the Creative Commons licence, and indicate if changes were made. The images or other third party material in this article are included in the article's Creative Commons licence, unless indicated otherwise in a credit line to the material. If material is not included in the article's Creative Commons licence and your intended use is not permitted by statutory regulation or exceeds the permitted use, you will need to obtain permission directly from the copyright holder. To view a copy of this licence, visit http://creativecommons.org/licenses/by/4.0/ The Creative Commons Public Domain Dedication waiver (http://creativecommons.org/publicdomain/zero/1.0/) applies to the data made available in this article, unless otherwise stated in a credit line to the data. 


\section{Background}

Polycystic ovary syndrome (PCOS) is a common endocrine and metabolic disease that affects women of childbearing age. There is no cure for PCOS and it is prone to relapse [1-3]. Although the etiology of PCOS is not yet completely understood, increasing evidence suggests that it is a multifactorial disease caused by environmental and genetic factors [4-7]. Environmental factors include environmental toxins, diet and nutrition, socioeconomic status, and geography, which are believed to affect the pathogenesis of PCOS [8-10]. Moreover, mutations, polymorphisms, and differential regulation of genes may contribute to the genetic pathogenesis of PCOS $[11,12]$. While a limited number of studies have reported relationships between PCOS and several candidate genes [13-15], no single gene has yet been identified as a biomarker.

Several studies have shown that an elevated homocysteine level may be related to the pathogenesis of PCOS [16-20]. A previous study found that elevated homocysteine levels could modulate M2 macrophage polarization via estrogen suppression, which promoted insulin resistance and adipose tissue inflammation in PCOS mice [20]. A multi-center, randomized, controlled trial with 936 participants showed that hyperhomocysteinemia, a medical condition characterized by an abnormally high level of homocysteine in the blood, increased the risk of pregnancy loss and reduced ovulation in people with PCOS [16].

In humans, the level of homocysteine is mainly affected by the metabolism of folic acid and methionine [21], where methylene tetrahydrofolate reductase (MTHFR) and methionine synthase reductase (MTRR) are the key enzymes [22-25]. Studies have shown that the activity of these two enzymes is mainly affected by three missense mutations, namely C677T (MTHFR), A1298C (MTHFR), and A66G (MTRR) [23, 26, 27]. The C677T mutation is the substitution of base $\mathrm{C}$ at the 677 site with $\mathrm{T}$, leading to the substitution of alanine with valine, which results in a thermolabile variant with reduced activity. The mutation of MTHFR A1298C is the substitution of base A to C at the 1298 site, leading to the substitution of glutamic acid with alanine, which reduces enzyme activity. The MTRR A66G mutation alters isoleucine into a methionine residue in the protein chain and subsequently disrupts the methionine/homocysteine cycle.

Therefore, we hypothesize that C677T, A1298C, and A66G may be risk factors for PCOS, acting through an increased level of homocysteine. In this case-control study, we performed a genotype analysis for the three missense mutations to elucidate if they were risk factors for PCOS. Furthermore, we examined whether the three mutations exerted their effect in PCOS by affecting the homocysteine level.

\section{Materials and methods}

\section{Participants}

This study recruited 150 premenopausal women with PCOS from the Department of Gynecology and Obstetrics, Zhujiang Hospital of the Southern Medical University (Guangzhou, PR China), between December 2018 and August 2019. All cases had a definitive diagnosis of PCOS, as per the Rotterdam diagnostic criteria [28]. A total of 300 age-matched, healthy, child-bearing women without PCOS were recruited as the control group for the same period. All cases and controls had no history of cancer, diabetes, hypertension, hyperprolactinemia, Cushing's syndrome, acromegaly, immune system disorders, a recent history of pregnancy, oral contraceptive pill for half a year prior to the study, and no previous treatment with folic acid.

Written informed consent for the study was provided by each participant. Ethical approval for the study was granted by the Institutional Research Ethics Committee of Zhujiang Hospital of Southern Medical University.

\section{Measures}

In this study, two fasting venous blood samples were extracted from each subject. One was collected in a normal EP tube for serum measurements, and the other was collected in an anticoagulant-treated EP tube for DNA extraction. Both were stored at $-80^{\circ} \mathrm{C}$ until use.

\section{Serum measurements}

Serum homocysteine levels were quantified using a cycling enzymatic method on a Mindray BS2000M automatic biochemical analyzer (Shenzhen Mindray Bio-Medical Electronics Co., Ltd, Shenzhen, PR China). The detection limit was determined by analyzing 6 replicates of the zero calibrators and 2 replicates of the lowest nonzero calibrator. If the concentration of homocysteine was more than $50 \mu \mathrm{mol} / \mathrm{L}$, the sample was manually diluted and retested. The reference range was $5-15 \mu \mathrm{mol} / \mathrm{L}$.

\section{DNA extraction and genotyping}

The DNA samples were extracted by using Magnetic Blood Genomic DNA Kit (Tiangen biochemical Technology co., Beijing, China), and were stored at $-20{ }^{\circ} \mathrm{C}$ until use.

Each DNA sample was assessed for MTRR A66G, MTHFR A1298C, and MTHFR C677T single nucleotide polymorphisms (SNPs) using the TaqMan-MGB SNPs Genotyping Assay (Applied Bio-systems Inc., Foster City, CA, USA). Fluorescence quantitative PCR was performed for TaqMan-MGB. The reagents and primers used were all from the Human MTHFR and MTRR Gene Polymorphism Detection Kit (Fluorescence PCR; SurExam Bio-Tech Co., Ltd, Guangzhou, PR China). 
The PCR amplification conditions were as follows: $95{ }^{\circ} \mathrm{C}$ denaturation for $10 \mathrm{~min}$ followed by 20 cycles of amplification $\left(92{ }^{\circ} \mathrm{C}\right.$ for $15 \mathrm{~s}$ and $60{ }^{\circ} \mathrm{C}$ for $\left.60 \mathrm{~s}\right)$ and 35 cycles of amplification $\left(89^{\circ} \mathrm{C}\right.$ for $15 \mathrm{~s}$ and $60{ }^{\circ} \mathrm{C}$ for $90 \mathrm{~s}$ ). All assays were replicated twice and the genotype allocation was determined by an automatic allele calling the quality value of 0.95 .

\section{Statistical analysis}

The differences in demographic and clinical characteristics were compared using the Chi-squared test or t-test. The deviation of genotype distribution was tested for Hardy-Weinberg equilibrium using the $x^{2}$ test. The associations between MTHFR/MTRR mutations and the risk of PCOS were assessed using logistic regression analyses under additive, dominant, and recessive models. Bonferroni correction was used to adjust for multiple comparisons. Linear regression was used to assess the associations between homocysteine and MTHFR/MTRR gene mutations. We further conducted a causal mediation analysis to test whether the association significance between MTHFR/MTRR mutations and PCOS was mediated via homocysteine level. Significance of the mediation effect was conducted using 5000 bootstrapped iterations mean indirect and direct effect. The bootstrapping test was performed using the SPSS PROCESS macro to test the statistical significance of the mediating effect [29].

For all multivariable models, potential confounders, including age, BMI, history of smoking, drinking, and hypertensive family history were adjusted. A two-tailed $P$-value of $<0.05$ was considered statistically significant. The SPSS 19.0 statistical package was used for all data analyses.

\section{Results}

\section{Participant characteristics}

Table 1 shows the characteristics of the participants. The mean age of the PCOS group was $27.02 \pm 4.76$ years, which was not significantly different from that of the control group $(p=0.363)$. Consistent with previous meta-analysis [30], the percentage of overweight or obesity in PCOS group is higher than the control group. The PCOS group subjects had a significantly lower folate level and higher homocysteine level compared to the control subjects. For the other characteristics, there was no significant difference between participants in the two groups.

For the Hardy-Weinberg equilibrium, no significant deviation from the expected population genotype proportions was detected at the MTHFR C677T $\left(\mathrm{X}^{2}=2.41\right.$, $P=0.12)$, MTHFR A1298C $\left(x^{2}=3.65, P=0.06\right)$, and MTRR A66G $\left(\chi^{2}=3.42, P=0.06\right)$.

Table 1 Demographic and clinical characteristics of the participants

\begin{tabular}{|c|c|c|c|}
\hline Characteristics & $\begin{array}{l}\text { Control group } \\
(n=300)\end{array}$ & $\begin{array}{l}\text { PCOS group } \\
(n=150)\end{array}$ & $P$ value \\
\hline Age (years), mean $\pm S D$ & $27.44 \pm 4.21$ & $27.02 \pm 4.76$ & 0.363 \\
\hline Height $(m)$, mean \pm SD & $1.60 \pm 0.03$ & $1.60 \pm 0.04$ & 0.994 \\
\hline Body mass index $\left(\mathrm{Kg} / \mathrm{m}^{2}\right)$, mean $\pm \mathrm{SD}$ & $20.31 \pm 2.03$ & $20.72 \pm 3.01$ & 0.131 \\
\hline Overweight or Obesity, n (\%) & $17(5.7 \%)$ & $17(11.3 \%)$ & 0.032 \\
\hline Smoking, n (\%) & $7(2.3 \%)$ & $5(3.3 \%)$ & 0.756 \\
\hline Drink, n (\%) & $6(2.0 \%)$ & $4(2.7 \%)$ & 0.910 \\
\hline Hypertensive family history, n (\%) & $13(4.3 \%)$ & $8(5.3 \%)$ & 0.635 \\
\hline Estradiol (pmol/L), median (IQR) & $171.00(135.5-218.75)$ & $141.50(98.75-206.25)$ & 0.856 \\
\hline Prolactin (ug/L), median (IQR) & $15.04(8.52-20.58)$ & $15.84(10.99-25.18)$ & 0.385 \\
\hline Testosterone (ug/L), median (IQR) & $0.49(0.42-0.53)$ & $0.54(0.44-0.68)$ & 0.315 \\
\hline Follicle-stimulating hormone (IU/L, median (IQR) & $8.05(6.45-13.55)$ & $7.05(5.95-7.93)$ & 0.102 \\
\hline Luteinizing hormone (IU/L), median (IQR) & $4.54(3.75-9.96)$ & $5.67(4.05-7.66)$ & 0.554 \\
\hline Cholesterol (mmol/L), median (IQR) & $4.66(3.77-5.02)$ & $4.37(3.87-4.79)$ & 0.157 \\
\hline Triglyceride (mmol/L), median (IQR) & $0.84(0.63-1.41)$ & $0.82(0.64-1.13)$ & 0.561 \\
\hline Fasting glucose (mg/dl), median (IQR) & $4.73(4.62-5.22)$ & $4.99(4.81-5.24)$ & 0.116 \\
\hline Fasting insulin $(\mu \mathrm{U} / \mathrm{ml})$, median (IQR) & $5.76(3.71-8.07)$ & $5.24(3.62-8.19)$ & 0.514 \\
\hline Folate $(\mathrm{ng} / \mathrm{mL})$, mean $\pm S D$ & $11.99 \pm 2.58$ & $10.49 \pm 3.83$ & $<0.001$ \\
\hline Homocysteine $(\mu \mathrm{mol} / \mathrm{L})$, mean $\pm \mathrm{SD}$ & $8.13 \pm 1.21$ & $10.07 \pm 2.06$ & $<0.001$ \\
\hline
\end{tabular}

Bold values indicate significance $(P<0.05)$ 
Table 2 Genotype distribution of MTHFR, MTRR mutations in the cases and controls according to additive, dominant, and recessive models

\begin{tabular}{|c|c|c|c|c|c|c|c|c|}
\hline Gene \& SNP & Model & Genotype & $\begin{array}{l}\text { PCOS Group } \\
\text { N (\%) }\end{array}$ & $\begin{array}{l}\text { Control Group } \\
\text { N (\%) }\end{array}$ & OR $(95 \% \mathrm{Cl})$ & $\begin{array}{l}P \\
\text { value }\end{array}$ & $\begin{array}{l}\text { Adjusted } \mathrm{OR}^{\mathrm{a}} \\
(95 \% \mathrm{Cl})\end{array}$ & $\begin{array}{l}P \\
\text { value }\end{array}$ \\
\hline \multirow[t]{7}{*}{$\overline{M T H F R ~ C 677 T ~}$} & Additive & CC & $67(44.7 \%)$ & $157(52.3 \%)$ & 1 & 0.184 & 1 & 0.352 \\
\hline & & $\mathrm{CT}$ & $68(45.3 \%)$ & 109 (36.3\%) & $1.462(0.964-2.217)$ & & $1.225(0.790-1.899)$ & \\
\hline & & $\Pi$ & $15(10.0 \%)$ & $34(11.3 \%)$ & $1.034(0.528-2.023)$ & & $0.753(0.372-1.524)$ & \\
\hline & Dominant & $C T+T$ & $83(55.3 \%)$ & $143(47.7 \%)$ & 1 & 0.126 & 1 & 0.628 \\
\hline & & CC & $67(44.7 \%)$ & 157 (52.3\%) & $0.735(0.496-1.090)$ & & $0.902(0.595-1.368)$ & \\
\hline & Recessive & $\pi$ & $15(10.0 \%)$ & $34(11.3 \%)$ & 1 & 0.669 & 1 & 0.263 \\
\hline & & $\mathrm{CC}+\mathrm{CT}$ & 135 (90\%) & $266(88.7 \%)$ & $1.150(0.605-2.186)$ & & $1.467(0.750-2.870)$ & \\
\hline \multirow[t]{7}{*}{ MTHFRA1298C } & Additive & $\mathrm{AA}$ & $65(43.3 \%)$ & 195 (65.0\%) & 1 & $<0.001$ & 1 & $<0.001$ \\
\hline & & $A C$ & $63(42.0 \%)$ & $91(30.3 \%)$ & $2.077(1.356-3.182)$ & & $2.142(1.376-3.336)$ & \\
\hline & & $\mathrm{CC}$ & $22(14.7 \%)$ & $14(4.7 \%)$ & $4.714(2.280-9.748)$ & & 3.755 (1.741-8.096) & \\
\hline & Dominant & $A C+C C$ & $85(56.7 \%)$ & 105 (35.0\%) & 1 & $<0.001$ & 1 & $<0.001$ \\
\hline & & $\mathrm{AA}$ & $65(43.3 \%)$ & 195 (65.0\%) & $0.412(0.276-0.615)$ & & $0.422(0.277-0.641)$ & \\
\hline & Recessive & CC & $22(14.7 \%)$ & $14(4.7 \%)$ & 1 & $<0.001$ & 1 & 0.008 \\
\hline & & $A A+A C$ & $128(85.3 \%)$ & 286 (95.3\%) & $0.285(0.141-0.575)$ & & $0.368(0.176-0.771)$ & \\
\hline \multirow[t]{7}{*}{ MTRR A66G } & Additive & AA & $82(54.7 \%)$ & $162(54.0 \%)$ & 1 & 0.014 & 1 & 0.028 \\
\hline & & $A G$ & $46(30.7 \%)$ & 118 (39.3\%) & $0.770(0.500-1.186)$ & & $0.694(0.442-1.088)$ & \\
\hline & & GG & $22(14.7 \%)$ & $20(6.7 \%)$ & $2.173(1.122-4.210)$ & & $1.796(0.902-3.572)$ & \\
\hline & Dominant & $\mathrm{AG}+\mathrm{GG}$ & $68(45.3 \%)$ & $138(46.0 \%)$ & 1 & 0.894 & 1 & 0.475 \\
\hline & & AA & $82(54.7 \%)$ & $162(54.0 \%)$ & $1.027(0.693-1.523)$ & & $1.162(0.770-1.753)$ & \\
\hline & Recessive & GG & $22(14.7 \%)$ & $20(6.7 \%)$ & 1 & 0.007 & 1 & 0.031 \\
\hline & & $A A+A G$ & $128(85.3 \%)$ & 280 (93.3\%) & $0.416(0.219-0.789)$ & & $0.481(0.247-0.935)$ & \\
\hline
\end{tabular}

$O R$ odds ratio, $\mathrm{Cl}$ confidence intervals

${ }^{a}$ Adjusted for potential confounders, including age, body mass index, folate, history of smoking, drinking, and hypertensive family history

Bold values indicate significance after Bonferroni correction for multiple comparisons $(P<0.016$, namely $0.05 / 3$ for three SNPs)

\section{Association of three missense mutations in MTHFR and MTRR genes and PCOS risk}

Table 2 shows the genetic associations between the three MTHFR/MTRR mutations and PCOS in both univariable and multivariable additive, dominant, and recessive models. The MTHFR A1298C showed a significant association with PCOS under all the three models, and the association remained significant after adjusting for potential confounders and Bonferroni correction for multiple testing was applied $(P<0.016)$. In the multivariable analysis of the additive model for MTHFR A1298C, a clear dose dependency was observed. Compared to the reference group (AA), those who carried one risk allele $(\mathrm{AC})$ had 2.142 times higher risk of developing PCOS, and those who carried two risk alleles (CC) had 3.755 times higher risk. The MTRR A66G was nominally associated with PCOS $(0.016<p<0.05)$ under the additive and recessive models, but not the dominant model. There was no association between MTHFR C677T and PCOS.

After removing obese women from both studied groups, we found similar results (data not shown).
Association of three missense mutations in MTHFR and MTRR genes and serum homocysteine level

Table 3 shows associations between the three MTHFR/ MTRR mutations and the serum homocysteine level for all participants after adjusting for potential confounders.

Table 3 Association of the three MTHFR/MTRR mutations and homocysteine levels

\begin{tabular}{llll}
\hline & Genotype & $\boldsymbol{\beta}^{\mathbf{a}}(\mathbf{9 5} \% \mathrm{Cl})$ & $\boldsymbol{P}$ value \\
\hline MTHFR C677T & CC & reference & \\
& CT & $0.034(-0.124-0.193)$ & 0.672 \\
& TT & $0.025(-0.141-0.192)$ & 0.764 \\
MTHFR A1298C & AA & reference & \\
& AC & $0.867(0.577-1.158)$ & $<\mathbf{0 . 0 0 1}$ \\
MTRR A66G & CC & $2.092(1.574-2.611)$ & $<\mathbf{0 . 0 0 1}$ \\
& AA & reference & \\
& AG & $-0.189(-0.499-0.122)$ & 0.233 \\
& GG & $0.704(0.189-1.219)$ & $\mathbf{0 . 0 0 7}$ \\
\hline
\end{tabular}

${ }^{a}$ Adjusted for potential confounders, including age, body mass index, folate, history of smoking, drinking, and hypertensive family history Bold values indicate significance $(P<0.05)$ 
Mutations in MTHFR A1298C and MTRR A66G were significantly associated with the serum homocysteine level. Participants having more risk alleles had a significant positive association with higher serum homocysteine levels than those with less. For example, compared to people who had no risk allele (AA), those who had one risk allele (AC) in MTHFR A1298C was $0.867 \mu \mathrm{mol} / \mathrm{L}$ higher in the homocysteine level, and two risk alleles (CC) was $2.092 \mu \mathrm{mol} / \mathrm{L}$ higher.

\section{Mediation analysis}

Table 4 shows whether the associations between three MTHFR/MTRR mutations and PCOS were mediated via homocysteine levels. The casual mediation analysis indicated that the effect of MTHFR A1298C on PCOS was mediated via the homocysteine level (indirect effect = 0.772 for AC; 1.861 for CC; $p<0.05$ for both). For MTRR A66G, only the effect of the phenotype GG on PCOS was mediated via the homocysteine level (indirect effect $=0.623 ; p<0.05$ ). For both the MTHFR A1298C and MTRR A66G, no significant direct effect was observed. There was no direct or indirect association between MTHFR C677T and homocysteine level on PCOS.

\section{Discussion}

Studies showed that an elevated homocysteine level may be related to the pathogenesis of PCOS. In this casecontrol study, we found that two mutations in homocysteine-related genes, namely MTHFR A1298C and MTRR A66G, were associated with the risk of PCOS, and the associations were mediated through influencing the level of homocysteine.

In our study, MTHFR A1298C was highly associated with PCOS after adjusting for potential confounders.
Compared to the wild-type genotype AA, mutant homozygote genotype AC had a 2.142 times higher risk of PCOS, and CC had 3.755 times higher risk of PCOS, which showed that the effect size was stronger for each additional risk allele $\mathrm{C}$. In agreement with our study, a recent meta-analysis demonstrated that MTHFR A1298C was associated with PCOS susceptibility [31]. For MTRR A66G, our results suggest an association with PCOS, but no significant association was found after multiple tests. A case-control study with 203 Brazilian participants showed that the polymorphic homozygous mutation of MTRR A66G was associated with protective factors for PCOS [32]. For the MTHFR C677T, we did not observe an association with PCOS; conflicting results have been reported, ranging from no observed association Poland [33] to the $\mathrm{T}$ allele being a risk factor for PCOS in the Korean population [34]. Such different conclusions of studies may be due to genetic mutations, race, region, and other factors, or due to differences in sample size.

Importantly, we also found that the association between MTHFR A1298C and PCOS was mediated by the serum homocysteine level. Mediation analysis examines what proportion of the SNP-PCOS association travels through homocysteine and acknowledges the fraction of the association that is independent of homocysteine. The result of the mediation analysis showed that the effect of A1298C on PCOS was through homocysteine. To our knowledge, this is the first study examining the potential mechanism underlying the association between genetic factors and the risk of PCOS. In addition, there is a biologically expected direction for the effect of A1298C on homocysteine and PCOS, in that A1298C with more risk alleles increased homocysteine levels and the risk of PCOS, which supports the mediation analysis results.

Table 4 Mediation analysis of associations between three MTHFR/MTRR mutations and PCOS risk (mediated by homocysteine)

\begin{tabular}{|c|c|c|c|c|}
\hline & & $\begin{array}{l}\text { Relative indirect effect } \\
(95 \% \mathrm{Cl})\end{array}$ & $\begin{array}{l}\text { Relative direct effect } \\
(95 \% \mathrm{Cl})\end{array}$ & $\begin{array}{l}\text { Total effect } \\
(95 \% \mathrm{Cl})\end{array}$ \\
\hline \multirow[t]{3}{*}{ MTHFR C677T } & CC & reference & reference & $-0.003[-0.004-(-0.002)]$ \\
\hline & $\mathrm{CT}$ & $0.062(-0.240-0.354)$ & $0.167(-0.337-0.670)$ & \\
\hline & $\pi$ & $0.069(-0.492-0.706)$ & $-0.431(-1.260-0.399)$ & \\
\hline \multirow[t]{3}{*}{ MTHFR A1298C } & AA & reference & reference & $0.102(0.052-0.168)$ \\
\hline & $A C$ & $0.772(0.464-1.132)$ & $0.155(-0.353-0.663)$ & \\
\hline & CC & $1.861(1.085-2.777)$ & $-0.054(-1.092-0.985)$ & \\
\hline \multirow[t]{3}{*}{ MTRR A66G } & $\mathrm{AA}$ & reference & reference & $0.014(-0.001-0.036)$ \\
\hline & $A G$ & $-0.169(-0.473-0.115)$ & $-0.344(-0.855-0.166)$ & \\
\hline & GG & $0.630(0.149-1.211)$ & $0.135(-0.693-0.963)$ & \\
\hline
\end{tabular}

All estimates obtained was adjusted for potential confounders, including age, body mass index, folate, history of smoking, drinking, and hypertensive family history, and used causal mediation analysis with SPSS's Process command

Relative Direct effects: independent effects of three missense mutations on PCOS risk. Relative Indirect effects: effects of three missense mutations on PCOS risk (mediated by homocysteine)

Bold values indicate significance $(P<0.05)$ 
Homocysteine is a protein that is synthesized in the body and, ideally, is in low concentrations in the blood [35]. Elevated homocysteine is a risk factor for many diseases, including PCOS and cardiovascular disease [36-41]. Therefore, our finding of the association between the homocysteine-related mutations and PCOS supports previous studies. However, to confirm the causality of the homocysteine levels and PCOS, a mendelian randomization study is needed. As the mutations of A1298C affect the function of MTHFR, drugs that treat MTHFR may reduce the risk of PCOS. Furthermore, as people with PCOS have a higher risk of cardiovascular disease, there may be an assumption that PCOS patients with a MTHFR A1298C AC/CC genotype may be prone to cardiovascular disease [42]. A key strength of this study is that we used mediation analysis to explain the biological rationality of the association between the risk mutations and PCOS. Furthermore, potential confounders were taken into account in the regression analyses.

However, several study limitations exist. Similar to other case-control studies, our study has limited verification of causality, but with the observations of other epidemiological supports from the Bradford-Hill Criteria [43], such as the temporal relation between the genes and PCOS outcome, the strong magnitude of effect, clear allele dose dependency, and biological plausibility, our findings increased the possibility of causality. Although the percentage of overweight or obesity in PCOS group is significantly higher than the control group (11.3\% vs. 5.7\%), there might be some inclusion bias since the pooled estimated prevalence of overweight and obesity in people with PCOS was 61\% [30]. Another limitation is that we used convenience samples to examine the relationship between the risk alleles and homocysteine level, which prevented control of the representativeness of the samples. This lack of control may cause biased samples and research results, and thus limit the wider application of the study. In addition, as the association between the three mutations with PCOS may be ethnic-specific and the interactions between genes and the environment may also modulate PCOS risk, the findings of the present study need to be verified in different populations and other larger cohort studies.

In conclusion, MTHFR A1298C and MTRR A66G were associated with PCOS, and MTHFR A1298C might affect the risk of PCOS by influencing the homocysteine level. Drugs that treat MTHFR may reduce the risk of PCOS for people with the MTHFR A1298C AC/CC genotype.

\section{Abbreviations}

PCOS: Polycystic ovary syndrome; MTHFR: Methylene tetrahydrofolate reductase; MTRR: Methionine synthase reductase; SNPs: Single nucleotide polymorphisms

\section{Acknowledgements}

We would like to thanks for the technical support provided by SurExam BioTech Co., Ltd, Guangzhou, PR China and also for all the friends who helped, supported and encouraged me, especially Miss. Yuan Feilan,

\section{Authors' contributions}

$M Y, F W Q, Z Y$ : designed the experiments and wrote the manuscript ; FWQ, $P Y, Z Y, W X Y, T D, Y L X$ : conducted the experiments; FWQ, ZY: analyzed the data; MY, LMJ, HYX, XYL, MWY, JJJ: recruit subjects. All of the authors gave final approval to the submitted version of the manuscript.

\section{Funding}

The study was supported by the National Natural Science Foundation of China [grant numbers: 81701418], the Science and Technology Planning Project of Guangdong province [grant number: 2014A020212667].

\section{Availability of data and materials}

The datasets used and analysed during the current study are available from the corresponding author on reasonable request.

\section{Ethics approval and consent to participate}

This study was approved by the Ethics Committee of Zhujiang Hospital, Southern Medical University and has been performed in accordance with the principles of Declaration of Helsinki. Written informed consent was obtained from all participants.

\section{Consent for publication}

Not applicable.

\section{Competing interests}

The authors declare no competing interests.

\section{Author details}

'Department of Gynecology, Obstetrics and Gynecology Center, Zhujiang Hospital, Southern Medical University, No.253, Gongye Middle Avenue, Haizhu District, 510280 Guangzhou, Guangdong, China. ${ }^{2} \mathrm{Clinical}$ Research Center, Zhujiang Hospital, Southern Medical University, 510280 Guangzhou, China. ${ }^{3}$ Department of Laboratory Medicine, Zhujiang Hospital, Southern Medical University, 510280 Guangzhou, China. ${ }^{4}$ Department of Obstetrics and Gynecology, Dongguan People's Hospital, 523000 Dongguan, China. ${ }^{5}$ Department of Obstetrics, Obstetrics and Gynecology Center, Zhujiang Hospital, Southern Medical University, 510280 Guangzhou, China.

${ }^{6}$ Department of Fetal Medicine and Prenatal Diagnosis, Obstetrics and Gynecology Center, Zhujiang Hospital, Southern Medical University, 510280 Guangzhou, China. ${ }^{7}$ Department of Emergency, Zhujiang Hospital, Southern Medical University, 510280 Guangzhou, China.

Received: 22 October 2020 Accepted: 17 December 2020

Published online: 07 January 2021

\section{References}

1. TREA Group. Revised 2003 consensus on diagnostic criteria and long-term health risks related to polycystic ovary syndrome (PCOS). Hum Reprod. 2004;19(1):41-7.

2. Azziz R. Polycystic ovary syndrome. Obstet Gynecol. 2018;132(2):321-36.

3. Legro RS, Arslanian SA, Ehrmann DA, Hoeger KM, Murad MH, Pasquali R, Welt CK. Diagnosis and treatment of polycystic ovary syndrome: an endocrine society clinical practice guideline. J Clin Endocrinol Metab. 2013; 98(12):4565-92.

4. Nardo LG, Patchava S, Laing I. Polycystic ovary syndrome: pathophysiology, molecular aspects and clinical implications. Panminerva Med. 2008;50(4):267.

5. Glintborg D, Andersen M. An update on the pathogenesis, inflammation, and metabolism in hirsutism and polycystic ovary syndrome. Gynecol Endocrinol. 2009;26(4):281-96.

6. Diamanti-Kandarakis E, Christakou C, Marinakis E. Phenotypes and enviromental factors: their influence in PCOS. Curr Pharm Design. 2012; 18(3):270

7. Diamanti-Kandarakis $\mathrm{E}$, Kandarakis $\mathrm{H}$, Legro RS. The role of genes and environment in the etiology of PCOS. Endocrine. 2006;30(1):19-26.

8. Rutkowska AZ, Diamanti-Kandarakis E. Polycystic ovary syndrome and environmental toxins. Fertil Steril. 2016;106(4):948-58. 
9. Dumesic DA, Oberfield SE, Stener-Victorin E, Marshall JC, Laven JS, Legro RS. Scientific statement on the diagnostic criteria, epidemiology, pathophysiology, and molecular genetics of polycystic ovary syndrome. Endocr Rev. 2015;36(5):487-525

10. Merkin SS, Phy JL, Sites CK, Yang D. Environmental determinants of polycystic ovary syndrome. Fertil Steril. 2016;106(1):16-24.

11. Azziz R. PCOS in 2015: New insights into the genetics of polycystic ovary syndrome. Nat Rev Endocrinol. 2016;12(3):183.

12. Day F, Karaderi T, Drong RM, Kraft A, Lin P, Huang N, Broer H, Magi L, Saxena $R$, et al. Large-scale genome-wide meta-analysis of polycystic ovary syndrome suggests shared genetic architecture for different diagnosis criteria. PLos Genet. 2018;14(12):e1007813.

13. Hiam M-A, Laven T. The genetics of polycystic ovary syndrome: an overview of candidate gene systematic reviews and genome-wide association studies. J Clin Med. 2019:8(10):1606.

14. Ruth KS, Beaumont RN, Tyrrell J, Jones SE, Tuke MA, Yaghootkar H, Wood AR, Freathy RM, Weedon MN, Frayling TM, et al. Genetic evidence that lower circulating FSH levels lengthen menstrual cycle, increase age at menopause and impact female reproductive health. Hum Reprod. 2016; 31(2):473-81.

15. Jones MR, Brower MA, Xu N, Cui J, Mengesha E, Chen YD, Taylor KD, Azziz R Goodarzi MO. Systems genetics reveals the functional context of PCOS loci and identifies genetic and molecular mechanisms of disease heterogeneity. PLoS Genet. 2015;11(8):e1005455.

16. Chang H, Xie L, Ge H, Wu Q, Wen Y, Zhang D, Zhang Y, Ma H, Gao J, Wang CC, et al. Effects of hyperhomocysteinaemia and metabolic syndrome on reproduction in women with polycystic ovary syndrome: a secondary analysis. Reprod Biomed Online. 2019;38(6):990-8.

17. Li D, Liu H, Fang Y, Huo J, Wu Q, Wang T, Zhou Y, Wang X, Ma X. Hyperhomocysteinemia in polycystic ovary syndrome: decreased betainehomocysteine methyltransferase and cystathionine $\beta$-synthase-mediated homocysteine metabolism. Reprod Biomed Online. 2018;37(2):234-41.

18. Diwaker A, Kishore D. Evaluation of plasma homocysteine levels in patients of PCOS. J Assoc Physicians India. 2018;66(10):17-20.

19. Fouani FZ, Fadaei R, Moradi N, Zandieh Z, Ansaripour S, Yekaninejad MS, Vatannejad A, Mahmoudi M. Circulating levels of Meteorin-like protein in polycystic ovary syndrome: a case-control study. PLOS ONE. 2020;15(4): e231943.

20. Qi X, Zhang B, Zhao Y, Li R, Chang HM, Pang Y, Qiao J. Hyperhomocysteinemia promotes insulin resistance and adipose tissue inflammation in PCOS mice through modulating M2 macrophage polarization via estrogen suppression. Endocrinology. 2017;158(5):1181-93.

21. Portillo F, Vázquez J, Pajares MA. Protein-protein interactions involving enzymes of the mammalian methionine and homocysteine metabolism. Biochimie. 2020;173:33-47.

22. Forges T, Chery C, Audonnet S, Feillet F, Gueant J. Life-threatening methylenetetrahydrofolate reductase (MTHFR) deficiency with extremely early onset: Characterization of two novel mutations in compound heterozygous patients. Mol Genet Metab. 2010;100(2):143-8.

23. Frosst P, Blom HJ, Milos R, Goyette P, Sheppard CA, Matthews RG, Boers GJ, den Heijer M, Kluijtmans LA, van den Heuvel LP. A candidate genetic risk factor for vascular disease: a common mutation in methylenetetrahydrofolate reductase. Nat Genet. 1995:10(1):111.

24. Holmes MV, Newcombe P, Hubacek JA, Sofat R, Ricketts SL, Cooper J, Breteler MM, Bautista LE, Sharma P, Whittaker JC, et al. Effect modification by population dietary folate on the association between MTHFR genotype, homocysteine, and stroke risk: a meta-analysis of genetic studies and randomised trials. The Lancet. 2011;378(9791):584-94.

25. Watkins D, Rosenblatt DS. Update and new concepts in vitamin responsive disorders of folate transport and metabolism. J Inherit Metab Dis. 2012;35(4):665-70

26. Weisberg I, Tran P, Christensen B, Sibani S, Rozen R. A second genetic polymorphism in methylenetetrahydrofolate reductase (MTHFR) associated with decreased enzyme activity. Mol Genet Metab. 1998;64(3):169-72.

27. Olteanu H, Munson T, Banerjee R. Differences in the efficiency of reductive activation of methionine synthase and exogenous electron acceptors between the common polymorphic variants of human methionine synthase reductaset. Biochemistry-Us. 2002;41(45):13378-85.

28. TREA Group. Revised 2003 consensus on diagnostic criteria and longterm health risks related to polycystic ovary syndrome. Fertil Steril. 2004;81(1):19-25.
29. Yuan Y, Li J, Jing Z, Yu C, Zhao D, Hao W, Zhou C. The role of mental health and physical activity in the association between sleep quality and quality of life among rural elderly in China: a moderated mediation model. J Affect Disorders. 2020;273:462-7.

30. Lim SS, Davies MJ, Norman RJ, Moran LJ. Overweight, obesity and central obesity in women with polycystic ovary syndrome: a systematic review and meta-analysis. Hum Reprod Update. 2012;18(6):618-37.

31. Zhu X, Hong X, Chen L, Xuan Y, Huang K, Wang B. Association of methylenetetrahydrofolate reductase C677T and A1298C polymorphisms with genetic susceptibility to polycystic ovary syndrome: a PRISMAcompliant meta-analysis. Gene. 2019;719:144079.

32. Santos TBD, Paula HKD, Balarin MAS, Silva-Grecco RL, Lima MFP, Resende EAMR, Gomes MKO, Cintra MTR. Can the genetic polymorphisms of the folate metabolism have an influence in the polycystic ovary syndrome? Arch Endocrinol Metab. 2019:63:501-8.

33. Szafarowska M, Segiet A, Jerzak MM. Methylenotetrahydrololate reductase A1298C and C677T polymorphisms and adverse pregnancy outcome in women with PCOS. Neuro Endocrinol Lett. 2016;37(2):141.

34. Ożegowska K, Bogacz A, Bartkowiak-Wieczorek J, Seremak-Mrozikiewicz A, Pawelczyk $L$. Is there an association between the development of metabolic syndrome in PCOS patients and the C677T MTHFR gene polymorphism? Ginekol Pol. 2016:87(4):246.

35. Finkelstein JD, Martin JJ. Homocysteine. Int J Biochem Cell Biol. 2000;32(4): 385-9.

36. Kozakova M, Morizzo C, Penno G, Shore AC, Nilsson J, Palombo C. Plasma homocysteine and cardiovascular organ damage in a population with a high prevalence of risk factors. J Clin Endocrinol Metab. 2020;105(8).

37. Mondal K, Chakraborty P, Kabir SN. Hyperhomocysteinemia and hyperandrogenemia share PCSK9-LDLR pathway to disrupt lipid homeostasis in PCOS. Biochem Biophys Res Commun. 2018;503(1):8-13.

38. Akhtar N. Is homocysteine a risk factor for atherothrombotic cardiovascular disease? J Am Coll Cardiol. 2007;49(12):1370-1.

39. Schiuma N, Costantino A, Bartolotti T, Dattilo M, Bini V, Aglietti MC, Renga M, Favilli A, Falorni A, Gerli S. Micronutrients in support to the one carbon cycle for the modulation of blood fasting homocysteine in PCOS women. J Endocrinol Invest. 2020;43(6):779-86.

40. Yilmaz N, Pektas M, Tonguc E, Kilic S, Gulerman C, Gungor T, Mollamahmutoglu $\mathrm{L}$. The correlation of plasma homocysteine with insulin resistance in polycystic ovary syndrome. J Obstet Gynaecol Res. 2008;34(3): 384-91.

41. Wu Y, Huang Y, Hu Y, Zhong J, He Z, Li W, Yang Y, Xu D, Wu S. Hyperhomocysteinemia is an independent risk factor in young patients with coronary artery disease in southern China. Herz. 2013;38(7):779-84.

42. Yaralı H, Yıldııır A, Aybar F, Kabakçı G, Bükülmez O, Akgül E, Oto A. Diastolic dysfunction and increased serum homocysteine concentrations may contribute to increased cardiovascular risk in patients with polycystic ovary syndrome. Fertili Sterili. 2001;76(3):511-6.

43. Cox LA. Modernizing the Bradford Hill criteria for assessing causal relationships in observational data. Crit Rev Toxicol. 2018;48(8):682-712.

\section{Publisher's Note}

Springer Nature remains neutral with regard to jurisdictional claims in published maps and institutional affiliations.

Ready to submit your research? Choose BMC and benefit from:

- fast, convenient online submission

- thorough peer review by experienced researchers in your field

- rapid publication on acceptance

- support for research data, including large and complex data types

- gold Open Access which fosters wider collaboration and increased citations

- maximum visibility for your research: over $100 \mathrm{M}$ website views per year

At $\mathrm{BMC}$, research is always in progress.

Learn more biomedcentral.com/submissions 